schools of arts and sciences might require their candidates to pass a set of examinations which would demonstrate a mastery of academic subjects somewhat comparable to that required for entrance into a European university. The requirements might be as follows : a good resding, writing and sperking knowledge of at least one foreign language; a knowledge of mathematics as far as the calculus; a knowledge of physics, chemistry and biology at the freshman college-level; the ability to write a competent essay ; a knowledge of American history and political constitutions at a sophisticated level; and a knowledge of English and American literature at a corresponding level.

The variety of colleges prevents any uniform set of standards for admission. Therefore, the colleges could not, even if they desired, greatly influence the high-school curricula. But the relatively homogeneous nature of the graduate and professional schools makes the formulation of standards possible. The effect of this formulation would influence both colleges and high schools.

\title{
CIRRHOSIS OF THE LIVER IN FRANCE
}

A $\mathrm{N}$ investigation was recently undertaken by the nutrition department of the Institut national d'Hygiene, Paris, into the role of alcohol in the rtiology of cirrhosis of the liver in France (W.H.O. Chronicle, 14, December 1960).

Cirrhosis of the liver is relatively more common in France than in the rest of Europe; the death-rate in 1956 was the highest in Western Europe $(32.5$ per 100,000 inhabitants, as against $2 \cdot 6$ in England and Wales and 13.6 in the Federal Republic of Germany). For many years the medical profession in France has attributed the high incidence of the disease to the excessive consumption of alcohol, and statistics from hospitals agree that 80-85 per cent of cirrhoses are alcoholic in origin. But the medical profession has been accused of prejudice, and wine merchants have put forward the argument that in a population of whom 80 per' cent are drinkers, it could be maintained that practically all illnesses are alcoholic in origin.

The survey was designed to answer five questions : did persons believed to have cirrhosis of alcoholic origin drink more before their illness than random controls of the same age, same sex and same social environment without cirnhosis; were they less well nourished (that is, is cirrhosis due to alcohol or to an associated nutritional deficiency); is the reduced food intake so often seen when cirrhosis becomes decompensated a cause or a consequence of the decompensation; can the amount of alcohol that causes cirrhosis be determined; and what part does wine play in the alcoholism of cirrhotics?

The survey was carried out in hospitals in Paris, Marseilles, and Nantes, all patients with alcoholic cirrhosis being questioned and a non-cirrhotic control boing chosen at random in the same department for each patient questioned. The physical activity at work and outside work, the height and the usual weight before cirrhosis began were recorded, and a detailed food questionnaire was devised to establish the daily food intake before and after the onset of the disease, as well as the quantity of alcohol absorbed daily. In addition, questions were asked to reveal the social background about the patients' family and parents, income, living conditions and standard of living.

In all, 116 cirrhotics and 116 controls were compared. They did not differ significantly in age, physical activity, weight, or calorie or protein intake; but the alcohol intake of the cirrhotics was found to be approximately 2.5 times greater than that of the non-cirrhotics. Before they fell ill, the cirrhotics has been just as well nourished as the others ; consequently, it was concluded that cirrhosis cannot be attributed to dietary deficiencies.

Only one out of the 116 patients with cirrhosis said that he had consumed less than $80 \mathrm{gm}$. of alcohol (that is, less than 1 litre of wine at $10^{\circ}$ ) daily. From this it may be inferred that alcoholic cirrhosis appears only when consumption of alcohol is greater than 1 litre a day. But 50 out of the 116 controls consumed 80-160 gm. of alcohol a day (1-2 litres of wine), and it was only in the category from $160 \mathrm{gm}$. of alcohol (2 litres of wine) up that controls tended to decrease in number ( 7 out of 116), while more than half the cirrhotics (64 out of 116) came within this range.

It seems reasonable to infer that cirrhosis is likeliest when the intake is between 2 and 2.5 litres of wine a day (172-212 gm. of alcohol). Cirrhosis can occur when it is 1 litre or more, but when it exceeds 2 litres the probability of its occurrence is much increased.

Is decreased food intake a decompensating factor in cirrhosis ? Apparently not to any marked degree : in 88 cases out of the 116 it failed to cause decompensation; thus even at this late state the nutritional deficiency is only associated, not causal.

Finally, the survey established that wine represented 80-90 per cent of the alcohol ingested.

\section{ELECTROLYTIC JUNCTION WITH AMPLIFYING PROPERTIES}

\author{
By B. LOVREČEK and B. KUNST \\ Institute of Physical Chemistry, Technical Department, University of Zagreb
}

N previous papers 1,2 it has been shown that the
rectification of altermating electric current at a
junction of two electrolytes is possible. This is
analogous to the same effect at a junction of $n$ - and
$p$-type semiconductors. It is to be expected that other
effects in semiconductors, for example, the amplifi- cation of electric current, have analogies in electrolytes. The purpose of this article is to report that this has been achieved.

The electric eircuit is similar to that used with Ovitron amplifiers ${ }^{3}$. The essential difference between the Ovitron and the device reported in this article is 